\title{
A ladder type structure: Rubidium diphenylacetate diphenylacetic acid
}

\author{
Manuela Ramos Silva, ${ }^{(1)}$ Ana Matos Beja, ${ }^{(1) *}$ José A. Paixão, ${ }^{(1)}$ Sérgio R. Domingos, ${ }^{(1)}$ \\ and Jesús Martín-Gil ${ }^{(2)}$
}

Received April 13, 2006; accepted August 14, 2006

Published Online November 7, 2006

A new rubidium complex, rubidium diphenylacetate diphenylacetic acid has been synthesised and characterised by single-crystal X-ray diffraction: triclinic, $P \overline{1}$ with $a=7.437(3) \AA, b=12.377(4) \AA, c=14.384(3) \AA \AA \alpha=107.08(2)^{\circ}, \beta=103.67(2)^{\circ}$, $\gamma=96.95(3)^{\circ}, M r=508.93, V=1203.6(6) \AA^{3}, Z=2$. The diphenylacetic molecules bridge the metallic ions forming an infinite ladder structure. Two strong hydrogen bonds link the organic moieties.

KEY WORDS: Ladder structure; hydrogen bonds; flexible molecule; diphenylacetic acid; rubidium complex.

\section{Introduction}

The formation of enantiomerically enriched products from achiral precursors without the intervention of chiral chemical reagents or catalysts is known as absolute asymmetric synthesis. This can be achieved if a molecular torsion causes a chiral conformation in an achiral molecule subsequently inducing crystallization into a chiral crystal structure. A common example is benzophenone that crystallizes in the chiral $P 2_{1} 2_{1} 2_{1}$ space group $^{1}$ and exhibits non-linear optical behaviour. ${ }^{2}$ It is the propeller like arrangement of the phenyl rings of benzophenone that promotes such chiral crystallization. Diphenylacetic acid is another molecule that can assemble in helical conformations. It has been used in absolute asymmetric

\footnotetext{
(1) CEMDRX, Departamento de Física, FCT, Universidade de Coimbra, 3004-516 Coimbra, Portugal.

(2) ETSIA, Universidad de Vallodolid, Avda Madrid 57, 34004 Palencia, Spain.

* To whom correspondence should be addressed; e-mail: ana@pollux.fis.uc.pt.
}

synthesis to provide chiral cocrystals namely with acridines. ${ }^{3,4}$ Searching for other compounds with the same features we have engaged in a structural study of diphenylacetic acid salts or adducts, such as the title compound, rubidium diphenylacetate diphenylacetic acid. The organic molecules of this compound assume a helical conformation with the two phenyl rings oriented like the blades of a propeller but they crystallize in the centrosymmetric $P \overline{1}$ group therefore with both enantiomers of the helical conformation in the crystal.

\section{Experimental}

\section{Preparation of Rubidium diphenylacetate diphenylacetic acid}

The title compound was prepared by neutralising an ethanolic solution of diphenylacetic acid (98\%, Aldrich) with rubidium hydroxide. Clear transparent single crystals of prismatic form grew from the solution by slow evaporation over a period of a few weeks, from which one was selected 
and used for the X-ray analysis. Before data collection, the quality of the crystal was checked by photographic methods (Lauegrams).

\section{Crystal structure determination}

A crystal of the title compound having approximate dimensions of $0.39 \mathrm{~mm} \times 0.34 \mathrm{~mm} \times$ $0.16 \mathrm{~mm}$ was placed in a glass fiber and mounted on a Enraf-Nonius CAD4 diffractometer. Diffraction data were collected at room temperature 293(2) K using graphite monochromated Mo K $\alpha$ $(\lambda=0.71073 \AA)$. The unit cell parameters were determined by least-squares refinement of diffractometer angles $\left(8.7^{\circ}<\theta<13.72^{\circ}\right)$ for 24 automatically centered reflections.

Data were processed using PLATON ${ }^{5}$ and an absorption correction (psi scan) was applied which resulted in transmission factors ranging from 0.869 to 0.944 . The data were corrected for Lorentz and Polarization effects. Reflections with $2 \theta \leq 50^{\circ}$ were used for structure solution and refinement.

The structure was solved by direct methods using SHELXS-97 ${ }^{6}$ and refined anisotropically (non-H atoms) by full-matrix least-squares on $F^{2}$ using the SHELXL- $97^{6}$ program. All the hydrogen atoms with exception of those of the carboxylic groups ( $\mathrm{H} 21$ and $\mathrm{H} 22)$ were placed at calculated positions and allowed to ride on their parent atoms using SHELXL-97 defaults. H21 and $\mathrm{H} 22$ were placed at special positions with an isotropic displacement parameter multiple of the parent atom $\mathrm{O} 2 \mathrm{~A}$ and $\mathrm{O} 2 \mathrm{~B}$, respectively. The final least-squares cycle based on 2683 observed reflections $[I>2 \sigma(I)]$ and 283 variable parameters, converged with $R=0.034$ and $w R=0.066$. The crystallographic details and selected interatomic distances and angles are given in Tables 1 and 2.

\section{Results and discussion}

\section{Crystal structure of the complex}

The structure of the title compound together with the atom-numbering scheme, is illustrated in Fig. 1. The formation of ladders is shown on
Table 1. Summary of Crystallographic Results

\begin{tabular}{|c|c|}
\hline Temperature $(K)$ & 293(2) \\
\hline Empirical formula & $\mathrm{C}_{28} \mathrm{H}_{23} \mathrm{O}_{4} \mathrm{Rb}$ \\
\hline Formula weight & 508.93 \\
\hline Wavelength $(\AA)$ & 0.71073 \\
\hline Crystal system & triclinic \\
\hline Space group & $P \overline{1}$ \\
\hline$a(\AA)$ & $7.437(3)$ \\
\hline$b(\AA)$ & $12.377(4)$ \\
\hline$c(\AA)$ & $14.384(3)$ \\
\hline$\alpha\left(^{\circ}\right)$ & $107.08(2)$ \\
\hline$\beta\left({ }^{\circ}\right)$ & $103.67(2)$ \\
\hline$\gamma\left({ }^{\circ}\right)$ & $96.95(3)$ \\
\hline Volume $\left(\AA^{3}\right)$ & $1203.6(6)$ \\
\hline$Z$ & 2 \\
\hline Calculated density $\left(\mathrm{g} / \mathrm{cm}^{3}\right)$ & 1.404 \\
\hline Absorption coefficient $\left(\mathrm{mm}^{-1}\right)$ & 2.088 \\
\hline$F(000)$ & 520 \\
\hline Crystal size $\left(\mathrm{mm}^{3}\right)$ & $0.39 \times 0.34 \times 0.16$ \\
\hline$\theta$ range for data collection (deg.) & $3.0-25.0$ \\
\hline Index ranges & $\begin{array}{l}-8 \leq h \leq 8 \\
-14 \leq k \leq 14 \\
-17 \leq l \leq 0\end{array}$ \\
\hline Reflections collected/unique & $4504 / 4211$ \\
\hline Completeness to $\theta=50^{\circ}$ & $99.7 \%$ \\
\hline Transmission factors $(\min / \max )$ & $0.869 / 0.944$ \\
\hline Data/restraints/parameters & $2683 / 0 / 283$ \\
\hline Goodness-of-fit on $F^{2}$ & 0.990 \\
\hline Final $\mathrm{R}$ indices $[I>2 \sigma(I)]$ & $0.034 / 0.066$ \\
\hline $\mathrm{R}$ indices (all data) & $0.109 / 0.078$ \\
\hline Largest diff. peak and hole $\left(\mathrm{e}^{-3}\right)$ & $-0.467 / 0.248$ \\
\hline CCDC Number & 602647 \\
\hline
\end{tabular}

Fig. 2, and Fig. 3 shows the packing diagram. Selected bond lengths and angles are listed in Table 2.

The diphenylacetic molecules bridge the metallic ions forming an infinite ladder struc-

Table 2. Selected Bond Lengths $\left(\AA^{\circ}\right)$ and angles $\left({ }^{\circ}\right)$

\begin{tabular}{lr}
\hline $\mathrm{C} 1 \mathrm{~A}-\mathrm{C} 2 \mathrm{~A}$ & $1.533(5)$ \\
$\mathrm{C} 2 \mathrm{~A}-\mathrm{C} 3 \mathrm{~A}$ & $1.519(5)$ \\
$\mathrm{C} 2 \mathrm{~A}-\mathrm{C} 9 \mathrm{~A}$ & $1.517(4)$ \\
$\mathrm{C} 1 \mathrm{~A}-\mathrm{O} 1 \mathrm{~A}$ & $1.221(4)$ \\
$\mathrm{C} 1 \mathrm{~A}-\mathrm{O} 2 \mathrm{~A}$ & $1.278(4)$ \\
$\mathrm{C} 1 \mathrm{~B}-\mathrm{C} 2 \mathrm{~B}$ & $1.532(5)$ \\
$\mathrm{C} 2 \mathrm{~B}-\mathrm{C} 3 \mathrm{~B}$ & $1.526(3)$ \\
$\mathrm{C} 2 \mathrm{~B}-\mathrm{C} 9 \mathrm{~B}$ & $1.512(4)$ \\
$\mathrm{C} 1 \mathrm{~B}-\mathrm{O} 1 \mathrm{~B}$ & $1.220(4)$ \\
$\mathrm{C} 1 \mathrm{~B}-\mathrm{O} 2 \mathrm{~B}$ & $1.289(4)$ \\
$\mathrm{O} 1 \mathrm{~B}-\mathrm{C} 1 \mathrm{~B}-\mathrm{O} 2 \mathrm{~B}$ & $125.1(3)$ \\
$\mathrm{O} 1 \mathrm{~A}-\mathrm{C} 1 \mathrm{~A}-\mathrm{O} 2 \mathrm{~A}$ & $124.4(3)$ \\
\hline
\end{tabular}




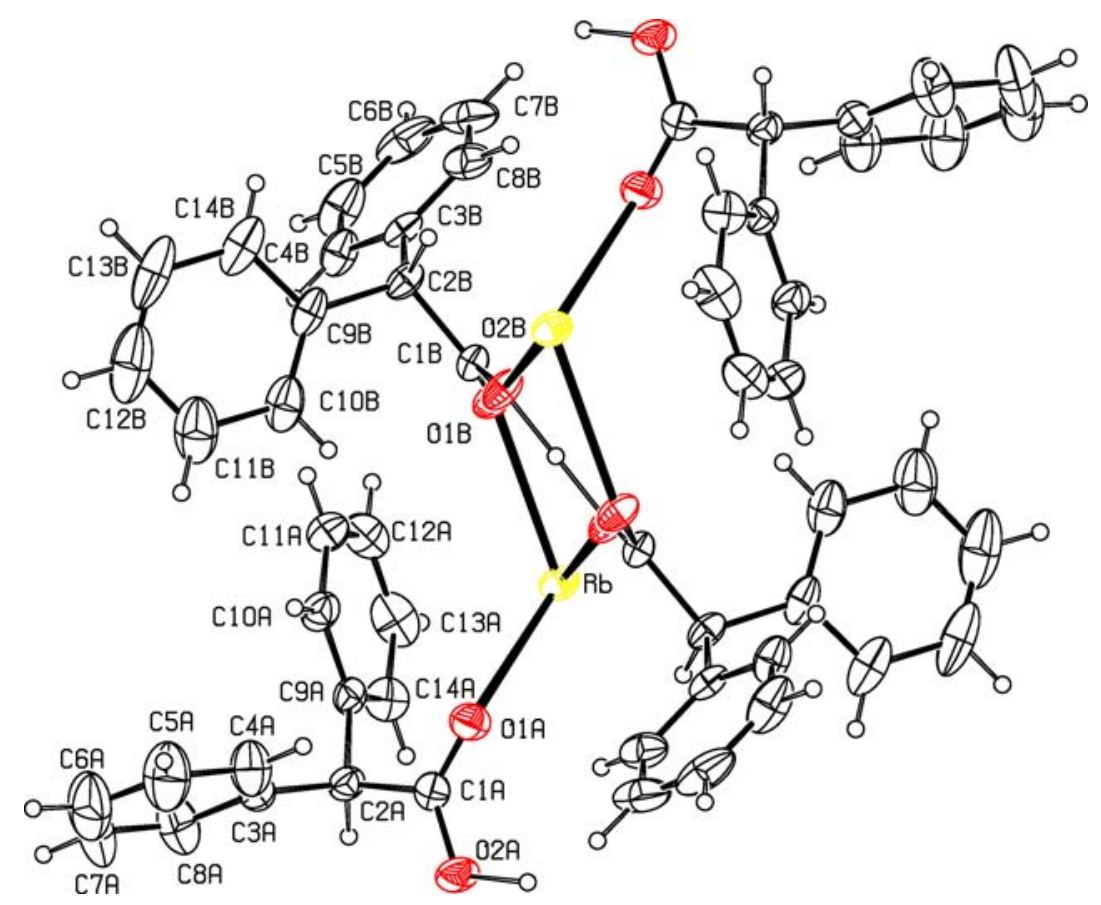

Fig. 1. ORTEPII plot of the title compound. Displacement ellipsoids are drawn at the $30 \%$ level.

ture similar to that seen in sodium diphenylacetate. ${ }^{7}$ In the previously reported structure, the carboxylate oxygen atoms and the $\mathrm{Na}^{+}$ions alternate at the vertices of a distorted cube centered at the origin of the $\overline{4}$ axis, forming an infinite columnar structure. At the present structure the rotoinversion axis is lost and the ladder climbs along an $\overline{1}$ axis. Each $\mathrm{Rb}^{+}$ion is coordinated with 4 oxygen atoms, 3 of those atoms belonging to the diphenylacetic B molecule and its symmetry relatives, and the remaining $(\mathrm{O} 1 \mathrm{~A})$ belongs to the A molecule. The B molecules, together with the alkali ions form the ladder which is a sequence of two wider steps $(\mathrm{O} 1 \mathrm{~B} . . \mathrm{Rb})$ and one narrower $\mathrm{O} 2 \mathrm{~B} \cdots \mathrm{O} 2 \mathrm{~B}^{\mathrm{i}}(i:-x+1,-y+1,-z+1)$, with widths $2.8640(18)$ and $2.452(5) \AA$, respectively (Fig. 2). The heights of the steps follow the sequence one larger $\left(\mathrm{Rb} \cdots \mathrm{O} 1 \mathrm{~B}^{\mathrm{ii}}, i i:-x+2\right.$,

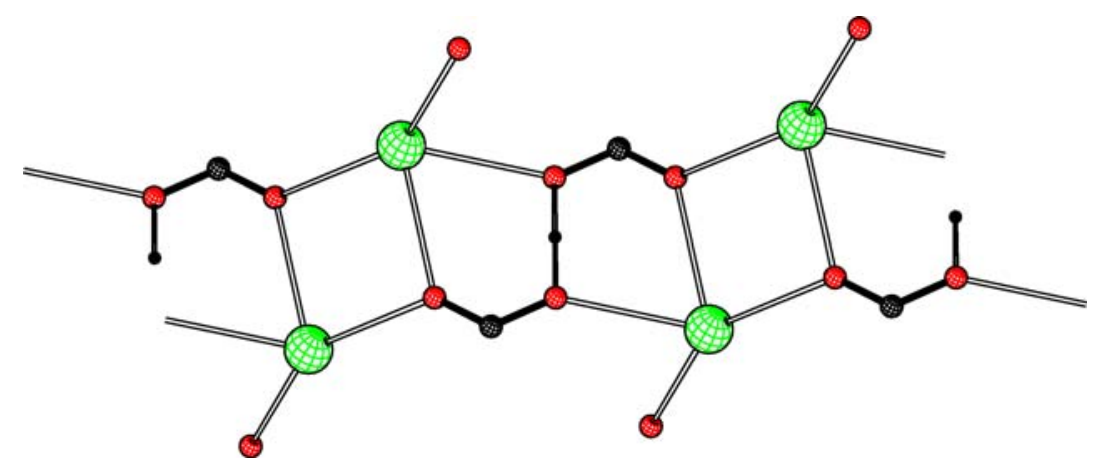

Scheme 


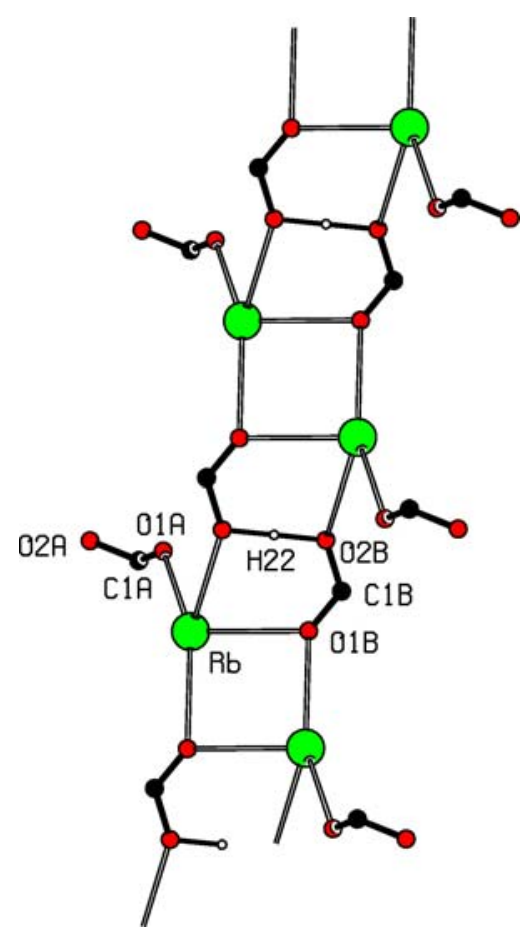

Fig. 2. Stacking of the $\mathrm{Rb} / \mathrm{O}$ core along the $a$ axis showing the ladder structure. The phenyl groups have been omitted for clarity.

$-y+1,-z+1)$ and two shorter $\left(\mathrm{Rb} \cdots \mathrm{O} 2 \mathrm{~B}^{\mathrm{i}}\right)$ of 2.8946(18) and 2.8639(18) $\AA$.

The A molecules just complete the alkali coordination without composing the ladder with a $\mathrm{Rb}-\mathrm{O}$ distance of $2.809(3) \AA$. The diago- nal $\mathrm{Rb}-\mathrm{Rb}^{\mathrm{ii}}$ (ii: $2-x, 1-y, 1-z$ ) distance is 4.1726(18) A.

The carboxylate skeleton defined by atoms $\mathrm{C} 1, \mathrm{C} 2, \mathrm{O} 1$ and $\mathrm{O} 2$ is planar to within $0.003 \AA$ for molecule $\mathrm{A}$ and $0.009 \AA$ for $\mathrm{B}$. The dihedral angle between the least-squares plane of the two phenyl rings is $80.98(13)^{\circ}$ and $79.94(13)$ for $\mathrm{A}$ and $\mathrm{B}$, respectively. In the $\mathrm{A}$ molecule the carboxylate group makes an angle of $83.89(15)^{\circ}$ and $76.11(13)^{\circ}$ with rings $\mathrm{C} 3 \mathrm{~A}-\mathrm{C} 8 \mathrm{~A}$ and $\mathrm{C} 9 \mathrm{~A}-$ $\mathrm{C} 14 \mathrm{~A}$, respectively. In the $\mathrm{B}$ molecule the carboxylate group makes angles of $85.67(7)^{\circ}$ and 80.66(11) with rings $\mathrm{C} 3 \mathrm{~B}-\mathrm{C} 8 \mathrm{~B}$ and $\mathrm{C} 9 \mathrm{~B}-\mathrm{C} 14 \mathrm{~B}$, respectively. Both molecules have the phenyl rings and the carboxylate planes with torsions around the single bonds to $\mathrm{C} 2$ in the same direction mimicking the blades of a propeller. The common sign of the torsion angles around $\mathrm{C} 2$, H2-C2-C1-O1 148.49 , H2-C2-C3-C4 144.0 , H2-C2-C9-C10 159.82 [for A] confirms this orientation $\left[-141.16,-151.13,-125.74^{\circ}\right.$ for $\mathrm{B}$, respectively]. There are interactions between the Rubidium ion and the and the $\pi$ electron clouds of the phenyl rings, the shortest Rb-centroid distances are 3.173(2) $\AA$ for ring $\mathrm{C} 3 \mathrm{~B}-\mathrm{C} 8 \mathrm{~B}^{\mathrm{ii}}$ and 3.292(2) for ring C9A-C14A.

There are two strong hydrogen bonds joining the organic moieties in this crystal. In each case a hydrogen atom is shared between a carboxylic group and its inverted counterpart. The highest peaks of the difference fourier synthesis

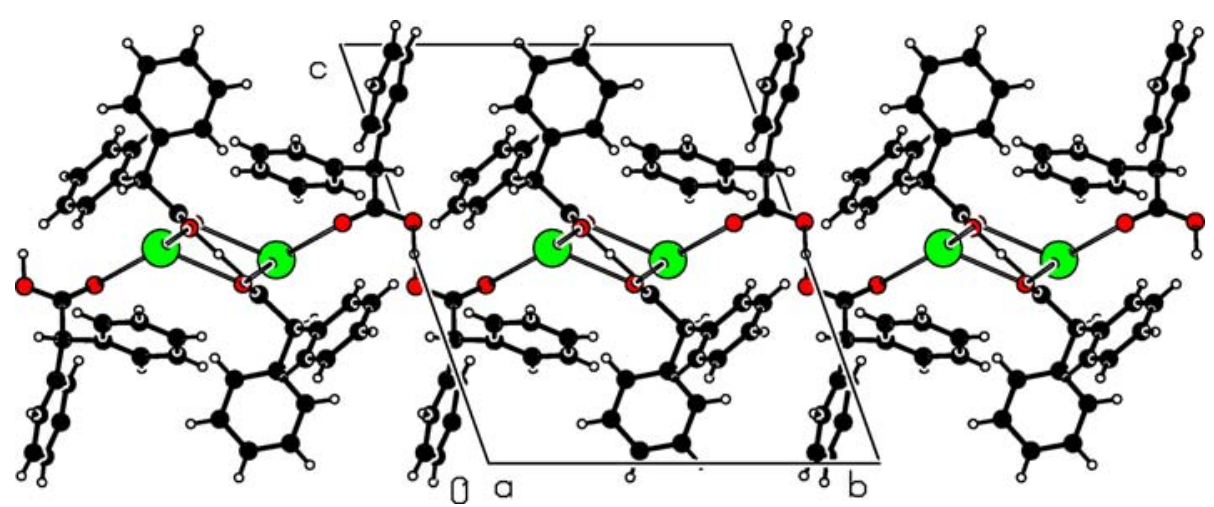

Fig. 3. Packing diagram of the complexes in the unit cell. 
at final stage of the refinement locate at the origins of the inversion axis, middle points of the bonds O2A …O 2 $\mathrm{A}^{\mathrm{iii}}$ (bond length 2.455(5) $\AA$, bond angle $180.00(11)^{\circ}$, iii: $\left.-x+1,-y,-z+1\right)$ and $\mathrm{O} 2 \mathrm{~B} \cdots \mathrm{O} 2 \mathrm{~B}^{\mathrm{i}}$ (bond length $2.452(5) \AA$, bond angle $\left.180.00(11)^{\circ}, i:-x+1,-y+1,-z+1\right)$. This might correspond to a highly symmetric situation with the shared hydrogen exactly midway between donor and acceptor or most likely, the shared hydrogen atom is statistically disordered being either close to one oxygen or to its symmetric counterpart.

Anyway the overall counting of the atoms shows that one of the protons was lost, so the negative charge of the organic moiety compensates the positive charge of $\mathrm{Rb}^{+}$. While one of the H-bonds forms one of the ladder steps, the other $\left(\mathrm{O} 2 \mathrm{~A} \cdots \mathrm{O} 2 \mathrm{~A}^{\mathrm{iii}}\right)$ joins the ladders together, forming layers parallel to the $a b$ plane, as seen in Fig. 3.

Supplementary materials Crystallographic data for structural analysis have been deposited with the Cambridge Crystallographic
Data Center, CCDC No. 602647. Copies of this information may be obtained free of charge on application to CCDC, 12 Union Road, Cambridge CB2 1EZ, UK (fax: + 441223336 033; e-mail: deposit@ccdc.cam.ac.uk or http://www.ccdc.cam.ac.uk).

\section{Acknowledgement}

This work was supported by Fundação para a Ciência e a Tecnologia under project POCI/ FIS/57876/2004.

\section{References}

1. Fleisher, E.B.; Sung, N.; Hawkinson, S. J. Phys. Chem. 1969, 72, 4311.

2. Sankaranarayanan, K.; Ramasamy, P. Cryst. Res. Technol. 2006, $41,225$.

3. Koshima, H.; Ding, K.; Chisaka, Y.; Matsuura, T. J. Am. Chem. Soc. 1996, 118, 12059.

4. Koshima, H. Mol. Cryst. Liq. Cryst. 2005, 440, 207.

5. Spek, A.L. J. Appl. Cryst. 2003, 36, 7.

6. Sheldrick, G.M. SHELXS97 and SHELXL-97; University of Gottingen: Germany, 1997.

7. Paixão, J.A.; Nascimento, F.V.; Matos Beja, A.; Ramos Silva, M. Acta Crystallogr. C 2000, 56, 168. 